\title{
Off-Lining to Tape Is Not Archiving: Why We Need Real Archiving to Support Media Archaeology and Ensure Our Visual Effects Legacy Thrives
}

\author{
Evanthia Samaras and Andrew Johnston
}

Evanthia Samaras Archivist/Researcher

Animal Logic Academy

University of Technology Sydney

15 Broadway Ultimo NSW 2007

Australia

evanthia.samaras@student.uts .edu.au

Andrew Johnston

Associate Professor

Faculty of Engineering

and IT Creativity and

Cognition Studios

Animal Logic Academy

University of Technology Sydney

15 Broadway Ultimo NSW 2007

Australia

andrew.johnston@uts.edu.au

\section{ABSTRACT}

This paper examines digital asset archiving and preservation practice in the visual effects (VFX) industry. The authors briefly summarize media archaeology theory and provide an overview of how VFX studios presently archive project assets and records, based on case study and interview research conducted with expert VFX practitioners from leading international studios. In addition, the authors propose that current practice could be improved by adopting archival science methods, including digital preservation practices. Doing so will support media archaeology studies of digital cultures over time and ensure that the legacy of VFX creative and technical production thrives for future generations.

Visual effects (VFX) is a creative and technical field of film production. It utilizes digital filming technologies and computer-generated imagery (CGI) in situations where visual elements cannot be achieved during live-action shooting. The film VFX industry is made up of over 500 studios spread across the globe, which service a small number of film studios [1]. As depicted in Fig. 1, work conducted by VFX studios involves a multitude of individual processes and outputs spanning from pre- to postproduction and often requires hundreds of highly specialized professionals to complete any given job.

Since its emergence into cinemas during the 1970s, VFX has evolved from a tentative filmmaking tool to a key component of modern filmmaking. However, despite its evolution into a significant part of the cinema

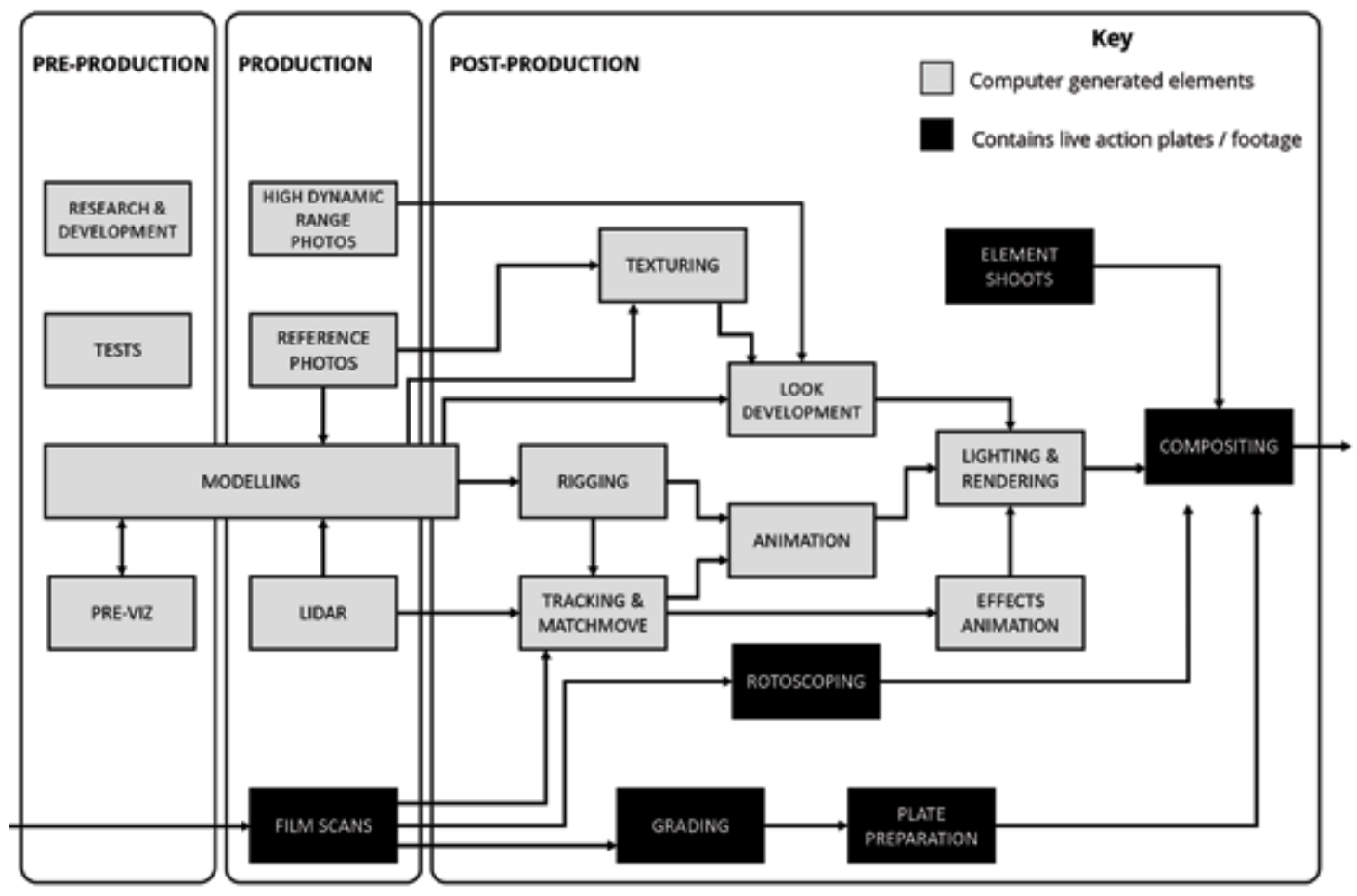

Fig. 1. VFX production workflow. (๑ Evanthia Samaras, adapted from [2]) 
discourse, we observed that the act of preserving and archiving VFX assets and records is not presently conducted consistently or effectively across the industry.

For VFX studios, "archiving" generally means moving data off-line to removable media storage (generally Linear Tape-Open (LTO) tape cartridges). This process fails to properly tackle ongoing preservation needs, including the access, reliability and usability of data over time. Plus, it does not address the reality that digital data stored on tape degrades over time-it is not a permanent storage solution.

For those of us in the archiving profession, real archiving is about safeguarding significant materials in all of their forms and formats over time [3] and developing solutions to issues such as format degradation, file obsolescence, ownership rights, authenticity and provenance [4]. Archiving is about protecting authoritative sources of information (plus supporting contextual data) and creating homes for our administrative, creative, social, political and cultural memories. It is a vocation that serves the special purpose of helping us understand the past to inform our present and future - a remit in alignment to the theoretical and philosophical "(un)discipline" [5] of media archaeology.

\section{Media Archaeology}

Media archaeology is a transdisciplinary field adopted by digital humanities, social science scholars, media practitioners and artists. It arose from early cinema studies during the 1980s and has developed into a multifaceted practice of investigating media cultures via understandings gained through past artifacts to uncover unseen, neglected and imagined media — a "(historical) reading against the grain" [6].

Rather than focusing exclusively on technological artifacts, media archaeologists (like archivists) recognize the importance of context. Through an apprehension of the rich layers of contextual metadata inherent in media artifacts, media archaeologists often go against the mainstream - focusing instead on the alternative histories of media cultures [7]. Media archaeology intersects with film history, media art and new media theory - three "branches" [8] that also traverse into VFX production.

Film VFX crosses into various other domains as it uses processes and tools comparable to digital games, animation and new media art production, and it creates innovative technologies and spectacles for the screen that can influence storytelling techniques and cinema culture. As depicted in Fig. 2, VFX archives could contain a myriad of contexts and stories to support media archaeological studies. As Jussi Parikka [9] writes, "The archive is becoming a key concept for understanding digital culture." Thus, preserving VFX production assets and records could have resounding benefits for media archaeology.

However, presently there is limited to no access to firsthand VFX artifacts beyond VFX and film studios. In fact, we observed that effective archival and preservation

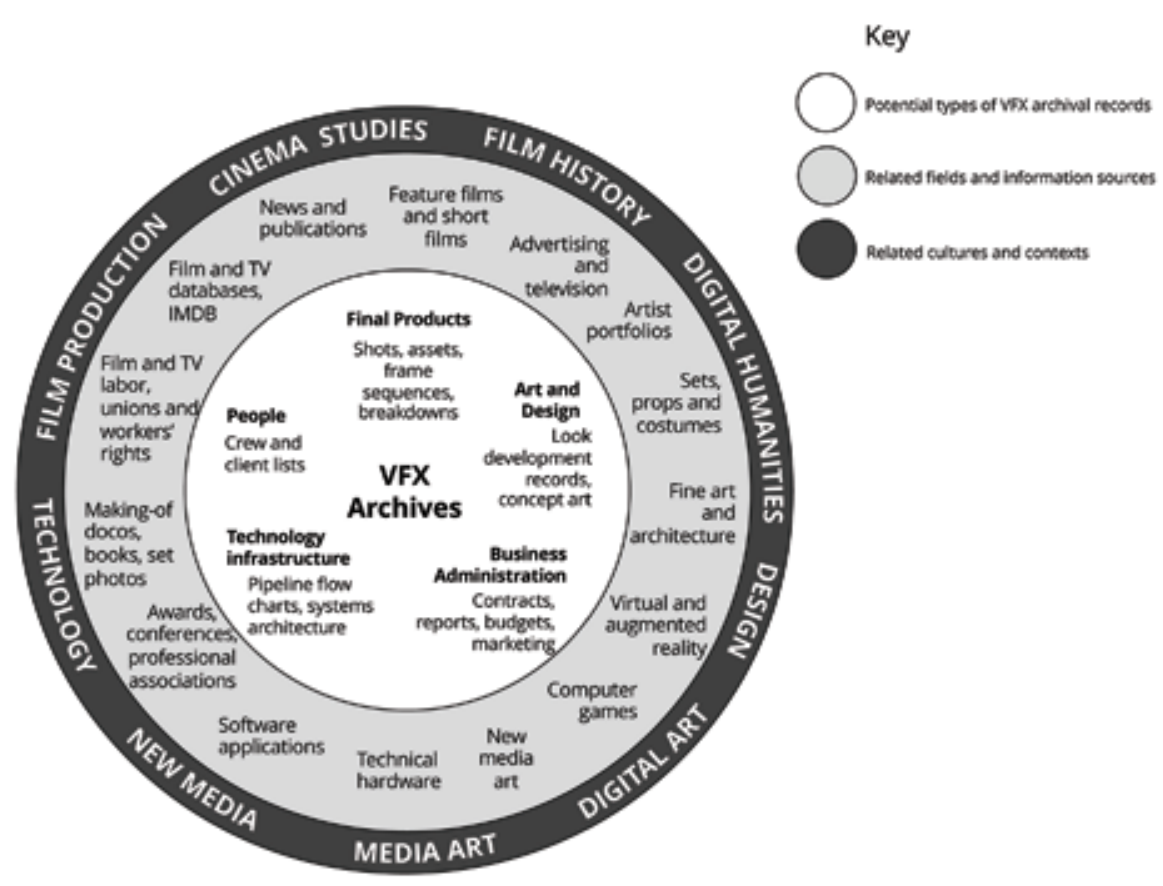

Fig. 2. VFX archives are related to many other domains, cultures and contexts. (C Evanthia Samaras) 
practice is not presently established within the VFX industry - meaning that artifacts are at risk of becoming unmanageable and lost over time.

\section{Research Method}

To gain an understanding of current archiving practice in the VFX industry, we conducted 13 semistructured interviews with expert practitioners from six major VFX studios operating in the Americas, Asia, Australasia and Europe. Each studio varies in size from roughly 150 to 600 people, depending on the scope of the individual project, and predominantly work on Hollywood blockbuster films and animated feature films. Two of the practitioners interviewed worked for studios that closed down. The interviewees were mainly senior-level staff and included producers, computer graphics (CG) supervisors, system administrators, data managers and pipeline developers.

For this research, we sought to apply a multiple case study approach. However, as Peta Darke, Graeme Shanks and Marianne Broadbent [10] note, convincing organizations to contribute to case study research can be a challenge as it's difficult to sell the immediate benefits of participation. Given this, we did not adopt a strict sampling methodology. Instead, we contacted a large range of disparate VFX companies in English-speaking countries and included in the research all of those that agreed to participate.

We applied constructivist grounded theory [11] to analyze the qualitative interview data with two phases of coding and memo writing. Through the interviews as well as a review of relevant publications about VFX archiving (of which there are very few), data management and production process as well as observation and survey techniques, we developed case studies to investigate and document multiple examples of real-world VFX archiving practice.

\section{Current VFX Archiving Practice}

Archiving in the VFX industry is a process managed under the auspices of IT and data management. As yet, we have not encountered VFX studio archivists. Archiving usually occurs at the end of a project or can happen during large-scale projects when a shot or sequence has been completed [12]. Similar to many backup and disaster recovery (DR) processes, archiving generally involves selecting data and writing it to removable media. CG supervisors and production staff often guide the selection process. Materials chosen for archiving usually relate to assets (and their dependencies) that contributed to the final shots (see Fig. 3). Or sometimes a complete project is archived.

Generally, data is archived onto LTO cartridges and tape libraries (see Fig. 4) and supporting tape archiving software is utilized to write and restore data. Minimal metadata is usually saved in the tape archiving software database (e.g. file name and file path). Instead most of the project asset metadata is usually retained online within VFX asset and shot management applications such as Shotgun [13], which means most of the archives' key contextual information is separate and disconnected.

Sometimes multiple copies of a project archive are written - one copy for onsite storage and one for offsite. In addition, a copy may also be delivered to the client along with the final shots. This requirement to deliver VFX material to clients is sometimes stipulated in VFX contracts but it is not always a requirement. As such, sometimes VFX studios have sole responsibility for retaining and managing VFX project archives well after a project has completed. This is despite the fact they are not usually the owners of the material.

VFX companies and artists are generally hired to produce work on behalf of a producer or studio company and are not usually considered copyright holders of their work. In the United States, this arrangement is known as a "work made for hire" [14]. This can pose a major obstacle to the archiving and digital 


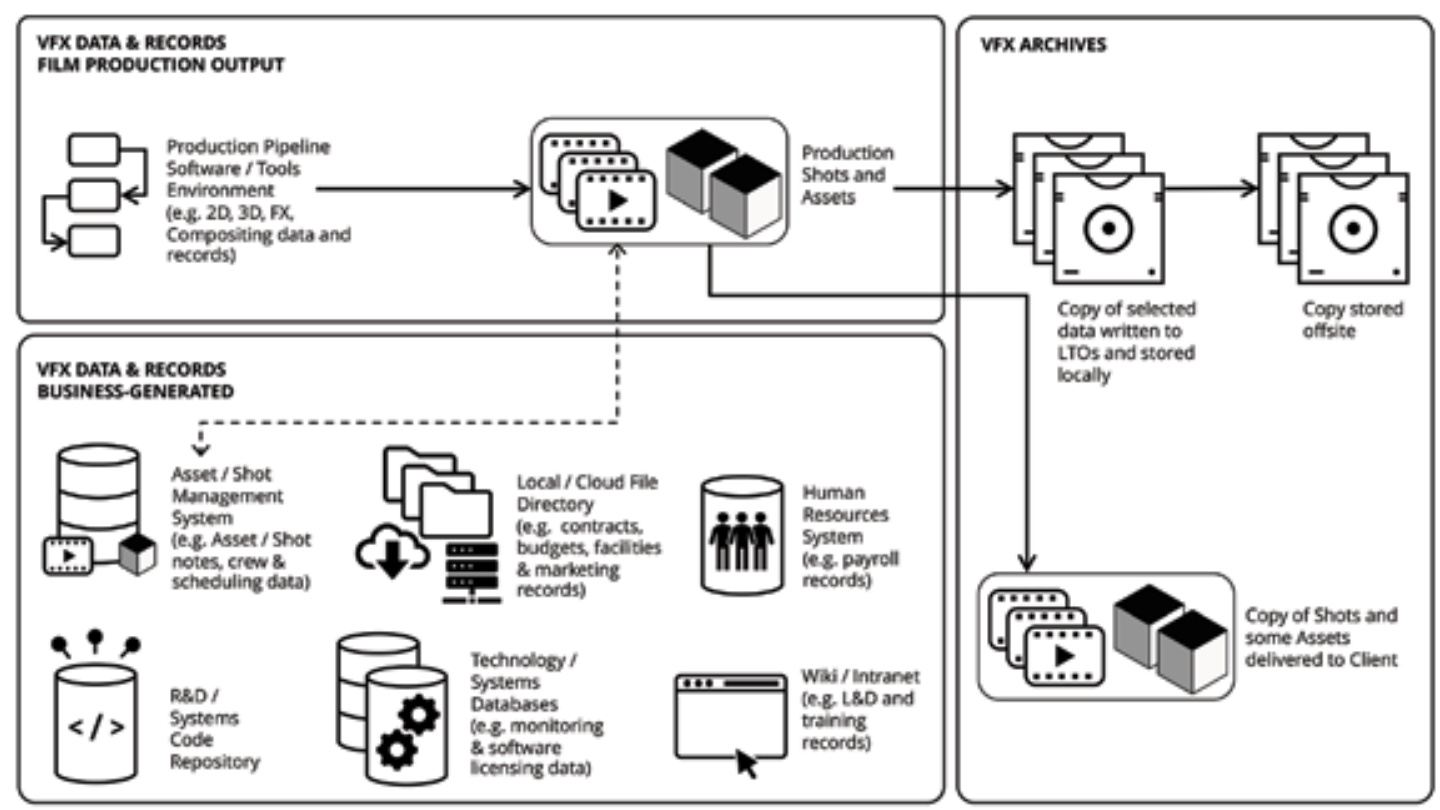

Fig. 3. VFX data and records and archiving practice. (๑ Evanthia Samaras)

preservation of VFX assets and records as legally the creators (and often custodians) of VFX archives have limited rights in using (and reusing) the material. Sometimes once a project is completed, VFX studios are instructed to purge their systems of all project material and must seek permission to keep anything that the VFX studio might want to use for marketing purposes. As one VFX supervisor explained:

Some shows are very intense about the deleting off your system . . . [they have] very proper procedures where people come in [to] verify and then everything related to the project is deleted off our system . . nothing is archived. [We] keep no assets, no plates and anything we did want to keep for showreel purposes had to be compiled into a list ... and approved [15].

\section{Opportunities for Improving Current Practice}

Contemporary archivists understand that to effectively archive and preserve digital materials over time, archival functions need to operate throughout the entire life span of the record [16]. A linear life cycle approach that relegates archiving at the end of production is not effective. Instead, a planned, continuum [17] approach should be adopted that develops archival policies, procedures and plans to support consistent practices and acknowledges archiving needs throughout production, in context of VFX technology, operational and creative praxes. This will help ensure that long-term preservation needs are continually met.

While writing data to tape preserves a bit stream (the ones and zeros) of the files that make up VFX projects, this process does not factor ongoing access, software availability and hardware obsolescence. A more holistic and planned approach could be considered that addresses ongoing accessibility and usability of the archives.

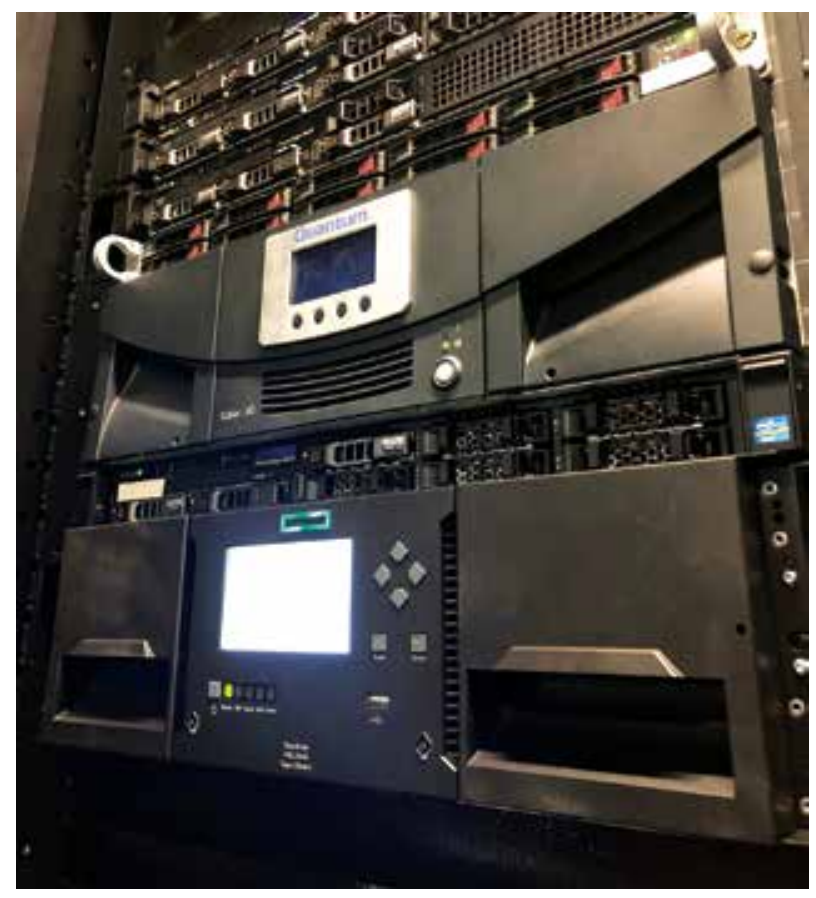

Fig. 4. Tape libraries at a VFX company. (๑ Evanthia Samaras) 
For example, if kept in the right conditions, LTO can have a shelf life of up to 30 years [18]. However, since its introduction, there have been multiple generations of LTO and unfortunately, the backward compatibility of the tapes does not extend beyond two generations [19]. Therefore, migration needs to be a constant consideration. In addition, description and access to archival materials managed on LTO could be greatly improved. While IT and data management practitioners utilize specialized technology to effectively write and restore tape data, identifying and reinstating archival collections with separately located metadata can be a difficult and error-prone task. As a VFX data wrangler indicates, joining the two is not always achieved seamlessly:

There's no direct link to anything we're archiving or backing up so although you can use Shotgun to search for it, it's then a very manual process to actually restore anything: there's no kind of direct link there at all [20].

We argue that VFX IT, data management, production and creative practitioners need to work closely with archivists to develop long-term archiving solutions that address issues such as tape format longevity, access and discovery. These solutions could incorporate work already being conducted in related fields of games preservation [21] and media art conservation [22] and adopt archival methods including:

- Access: developing tools such as catalogs to ensure users have the ability to locate relevant information and arranging appropriate permissions for archival materials that consider custodianship, legal, privacy, confidentiality and security requirements [23]. As Paul Charisse [24] indicates, "film companies are notoriously protective over their property and the legal web of intellectual and property copyright issues that surround this content would possibly provide the biggest challenge of all. ..." To support media archaeology of VFX over time and ensure VFX materials do not remain locked under copyright for decades (or deleted prematurely), usage rights negotiations could be made with owners to facilitate access.

- Appraisal: defining and systematically applying criteria for the identification of records to determine how long they should be kept and if they have permanent value. The value proposition can originate from assessing certain functions and activities and considering expected use by business or society over time [25].

- Arrangement: "[o]rganizing materials with respect to their provenance and original order, to protect their context and to achieve physical or intellectual control over the materials; [and] the organization and sequence of items within a collection" [26]. This is a process that archivists undertake to meet the foundational archival principle of respect des fonds.

- Description: developing accurate and appropriate representations and detecting and explaining content and contextual information about archival material to support access [27].

- Preservation: applying required tasks to maintain access to materials over time, beyond the life of changing media, technology and business practices and systems.

\section{Benefits of Real Archiving VFX}

By applying considered archival appraisal methods, only materials of ongoing value will be selected and retained in the long term as archives. Ross Harvey [28] suggests appraisal and selection are vital in the digital age because it is not realistic in resource terms (nor desirable) to sustain access to all digital materials indefinitely. As a result of this approach, valuable archival storage space in VFX studios will not be filled up with temporary-value materials.

Also, by creating clear access and custodianship models for VFX archives, copyright owners could assign rights, transfer custody to an archive, library or museum, or establish their own effective access regimes. 
This type of model could also lift current expectations on VFX studios to maintain archives for periods longer than what is required for their business practices.

Archiving VFX records may also reveal more comprehensive information about who actually contributed to VFX on a film. As a VFX data operations specialist states, "At the moment you have the issue where technically all artists that work on a film should be credited, but they're not" [29]. Given this unfortunate (and common) reality, there is a lack of authoritative evidence about people's genuine professional contribution to VFX production.

In addition, if real archiving practice is applied within the VFX industry, the legacy of VFX has an improved chance of flourishing and thriving into the future. The ongoing preservation and access to VFX assets and records would facilitate media archaeology studies that stretch beyond secondary sources of information such as behind-the-scenes videos, publications such as Cinefex VFX journal and websites including the Internet Movie Database (IMDb) and Art of VFX. Access to VFX archives could help to uncover hidden histories of VFX people, processes and technologies and reveal what it was really like "working in the trenches of VFX" [30]. This could shed light upon the various creative and technical decisions that contributed to digital art and technology evolution, and cinema storytelling and discourse.

\section{Conclusion and Future Work}

This paper has argued that VFX practice should be preserved because, since its introduction into the cinematic domain over four decades ago, it has flourished into a significant part of our art and entertainment culture and intersects with film history, media art and new media theory.

Drawing from initial findings gained through interviews and case study research conducted with expert VFX practitioners, the paper has provided an overview of current archiving practice in the VFX industry, as well as presented the argument that VFX archives could offer "real-world evidence-richer and more complete stories about the people, business, process, technology and outputs of the film VFX industry" [31].

The long-term preservation and archiving of VFX materials provides more avenues of exploration for media archaeology and helps illustrate multiple perspectives and realities of VFX production and other domains and contexts of study. However, achieving this requires further investigations and research within the VFX industry, as well as the practical application of archival methods that consider technical obsolescence, usability and availability issues.

Archives are a "unique and irreplaceable heritage passed from one generation to another" [32]. VFX assets and records preserved over time as archives will form valuable future media archaeological artifacts and will help ensure our VFX legacy thrives into the future. Effective VFX archiving will ensure that the life and practices of an ever-changing digital cinematic age will be better understood for decades to come.

\section{Acknowledgments}

Thank you to Dr. Andrew Bluff for your input on this paper and your general feedback and encouragement throughout the research. We would like to express our great appreciation to the various studios and their staff that took time out of their busy VFX production schedules to share their practices and knowledge.

\section{References and Notes}

1. M. Curtin and K. Sanson, eds., "Fringe City: Editors' Introduction" in Voices of Labor: Creativity, Craft, and Conflict in Global Hollywood (Oakland: Univ. of California Press, 2017) p. 201.

2. A. Whitehurst, The Visual Effects Pipeline, www.andrew-whitehurst.net/pipeline.html, accessed 15 March 2019. 
3. P. Conway, "Archival Preservation Practice in a Nationwide Context," The American Archivist 53, No. 2, $204-222$ (1990).

4. Provenance relates to the context of creation - the origin and creating agents of records. See T. Cook, "Electronic Records, Paper Minds: The Revolution in Information Management and Archives in the Post-Custodial and PostModernist Era," Archives and Manuscripts 22, No. 2, 300-328 (1994).

5. J. Van Gorp et al., "Digital Media Archaeology: Digging into the Digital Tool AVResearcherXL," VIEW Journal of European Television History and Culture 4, No. 7, 38-53 (2015) p. 40.

6. W. Strauven, "Media Archaeology: Where Film History, Media Art, and New Media (Can) Meet" in Preserving and Exhibiting Media Art: Challenges and Perspectives, J. Noordegraaf et al., eds. (Amsterdam: Amsterdam Univ. Press, 2013) p. 64.

7. G.E. Bravo et al., "The Interactive Image: A Media Archaeology Approach,” Leonardo 50, No. 4, 368-375 (2017).

8. Strauven [6] p. 64.

9. J. Parikka, What is Media Archaeology? (Cambridge, U.K.: Polity Press, 2012) p. 15.

10. P. Darke, G. Shanks and M. Broadbent, "Successfully Completing Case Study Research: Combining Rigour, Relevance and Pragmatism," Information Systems Journal 8, No. 4, 273-289 (1998).

11. This form of grounded theory was selected as it recognizes that theory is not derived objectively from the data but can be shaped by shared experiences and relationships with participants and other data sources (such as literature). See K. Charmaz, "Grounded Theory: Objectivist and Constructivist Methods" in The SAGE Handbook of Qualitative Research, N.K. Denzin and Y.S. Lincoln, eds., 2nd Ed. (Thousand Oaks, CA: SAGE, 2000) pp. 509-536 and B.G. Glaser and A.L. Strauss, The Discovery of Grounded Theory: Strategies for Qualitative Research (New Brunswick, NJ: AldineTransaction, 1967) for general information about grounded theory.

12. T. Green et al., "Systems Infrastructure," Production Pipeline Fundamentals for Film and Games (Burlington, MA: Focal Press, 2014).

13. See www.shotgunsoftware.com, accessed 7 January 2019.

14. Copyright Act of 1976, U.S.A.

15. VFX supervisor, 30 October 2018.

16. S. McKemmish et al., "The Archives" in Archives: Recordkeeping in Society (Wagga Wagga, Australia: Centre for Information Studies, Charles Sturt University, 2005).

17. Australian archivist Frank Upward established the Records Continuum theory in the 1990s at Monash University. It is a postmodern model that supports digital archiving and recordkeeping. See F. Upward, "Modelling the Continuum as Paradigm Shift in Recordkeeping and Archiving Processes, and Beyond - a Personal Reflection," Records Management Journal 10, No. 3, 115-139 (2005).

18. N. Dodgson, J. Patterson and P. Willis, "What's up Prof? Current Issues in the Visual Effects and Post-Production Industry," Leonardo 43, No. 1, 92-93 (2010).

19. M. Perlmutter, “The Lost Picture Show," IEEE Spectrum 54, No. 5, 26-31 (2017).

20. VFX data wrangler, 30 October 2018.

21. See R. Bettivia, "Where Does Significance Lie: Locating the Significant Properties of Video Games in Preserving Virtual Worlds II Data," International Journal of Digital Curation 11, No. 1, 17-32 (2016) and J. McDonough and R. Olendorf, "Saving Second Life: Issues in Archiving a Complex, Multi-User Virtual World," International Journal of Digital Curation 6, No. 2, 89-108 (2011).

22. See P. Innocenti, "The Pursuit of Authenticity in Preserving Digital Art," 2015 Digital Hertiage International Congress (Granada: IEEE, 2015) pp. 425-430.

23. Society of American Archivists, Access, www2.archivists.org/glossary/terms/a/access, accessed 7 January 2019.

24. P. Charisse, "Archiving Software and Content in Visual Film Effects: An Insider's Perspective," in Preserving Complex Digital Objects, J. Delve and D. Anderson, eds. (London: Facet Publishing, 2014) p. 293.

25. B. Anderson, F. Eaton and S.W. Schwartz, "Archival Appraisal and the Digital Record: Applying Past Tradition for Future Practice," New Review of Information Networking 20, No. 1-2, 3-15 (2015).

26. R. Pearce-Moses, A Glossary of Archival and Records Terminology (Chicago: Society of American Archivists, 2005) pp. 34-35.

27. International Council on Archives (ICA), $\operatorname{ISAD}(G)$ : General International Standard Archival Description (Ottawa: ICA, 2000).

28. R. Harvey, "Appraisal and Selection,” DCC Digital Curation Manual, June 2006, www.dcc.ac.uk/resources /curation-reference-manual/completed-chapters/appraisal-and-selection, accessed 7 January 2019.

29. VFX data operations specialist, 6 April 2018.

30. VFX head of R\&D, 12 March 2018.

31. E. Samaras and A. Johnston, "Fleeting Film: Using Story to Seek Archival Permanence in the Transitory and Globalized Digital Visual Effects Industry," Preservation, Digital Technology and Culture 47, No. 1, 12-22 (2018) p. 18.

32. ICA, Universal Declaration on Archives (Paris: UNESCO, 2011) p. 1. 